\title{
НАБЛЮДЕНИЕ КАК ПЕДАГОГИЧЕСКИЙ МЕТОД В РАЗВИТИИ КОММУНИКАТИВНЫХ СПОСОБНОСТЕЙ СТУДЕНТОВ КОЛЛЕДЖА
}

\author{
Лукьянова Людмила Александровна \\ аспирант кафедры педагогики \\ Научный руководитель: Найн Александр Альбертович \\ д.п.н., профессор \\ ФГБОУ ВО «Уральский государственный \\ университет физической культуры»
}

\begin{abstract}
Аннотация: В настоящее время быть успешным человеком, значит обладать силой характера и иметь развитые коммуникативные способности. Формирование коммуникативных способностей студентов начинается с рождения. Определяющим фактором во многих делах являются их взаимоотношения с окружающими. А коммуникативные способности - это залог хороших отношений. Рассмотрим метод наблюдения, как один из древнейших методов познания действительности. Наблюдение направлено на вскрытие существенных взаимосвязей и отношений в наблюдаемой действительности. Оно позволяет широко и многомерно охватить события, описать взаимодействие всех его участников.
\end{abstract}

Ключевые слова: наблюдение, педагогический метод, коммуникативные способности, студенты колледжа, развитие речи.

\section{OBSERVATION AS A PEDAGOGICAL METHOD IN THE DEVELOPMENT OF COMMUNICATIVE ABILITIES OF COLLEGE STUDENTS}

\section{Lukyanova Lyudmila Aleksandrovna Nain Alexander Albertovich}

\begin{abstract}
Currently, being a successful person means having strength of character and having developed communication skills. The formation of students' communicative abilities begins from birth. The determining factor in many cases is their relationship with others. And communication skills are the key to a good relationship. Let's consider the method of observation as one of the oldest methods of cognition of reality. Observation is aimed at revealing essential relationships and
\end{abstract}


relationships in the observed reality. It allows you to cover events in a broad and multidimensional way, to describe the interaction of all its participants.

Key words: observation, pedagogical method, communicative abilities, college students, speech development.

Актуальность проблемы исследования. Важнейшее достоинство метода наблюдения заключается в том, что оно осуществляется одновременно с развитием коммуникативных способностей студентов колледжа. Открывается возможность непосредственно воспринимать поведение людей в конкретных условиях в настоящем времени. Существуют удобные и приемлемые упражнения для развития коммуникативных способностей. Они помогут научиться сглаживать конфликты, развить убедительную речь, приобрести навыки эффективной самопрезентации и повысить доверие. Определить, насколько развиты социально-коммуникативные навыки у студентов колледжа, можно по тому, как активно, интенсивно и продолжительно они поддерживают контакт с другими студентами, насколько широк круг их общения. Для общения немаловажным является хорошая речь. Всем известно, что хорошая дикция заставляет прислушиваться к говорящему человеку и больше доверять его мнению. К тому же подобное умение нередко способствует карьерному росту, в особенности, если для выполнения должностных обязанностей необходимо часто общаться с людьми.

Теоретическая значимость исследования. Развитие коммуникативных умений и навыков начинается еще в детском возрасте и на это влияет множество факторов, таких как особенности воспитания, микроклимат в семье, образ жизни и другие немаловажные вещи. Если ребенок не получает определенного коммуникативного опыта, во взрослом возрасте он может быть замкнутым и неуверенным. Важно помнить, что развитие социально-коммуникативных навыков доступно в любом возрасте. Наиболее значимое место в развитии коммуникативных способностей занимает развитие речи. Разви́тие ре́чи (или онтогенез речи, ср. также англ. Language development) - широко используемое комплексное обозначение процессов, этапов и методик, связанных с овладением средствами как устной, так и письменной речи (языка), характеризующими в свою очередь развитие его навыков коммуникации, вербального мышления и литературного творчества.

Коммуникативные способности. Коммуникативные способности важны для формирования круга общения, знакомства, обретения друзей и ведения 
переговоров, покупки товаров и услуг, заключения контрактов и ведения бизнеса, выстраивания продуктивных взаимоотношений, разрешения конфликтов и поиска взаимопонимания с окружающими. И если студенты не умеют общаться, то они могут встретить немало проблем и трудностей, как в личной жизни, так и в профессиональной среде [4, стр. 111].

Структура коммуникативных способностей включает в себя множество компонентов, среди которых:

- интеракционные умения (связаны с «подачей себя» и умением «настраиваться» на собеседника);

- волевые качества;

- восприятие и интерпретация вербальных и невербальных сигналов;

- способность к пониманию подтекста и контекста;

- способность к применению знаковых систем для решения разных коммуникативных задач и т. д.

В нашем исследовании мы акцентируем внимание на интеракционных умениях студентов колледжа, которые и будут для нас объектом наблюдения.

Наблюдение. Термин «наблюдение» имеет несколько значений: житейское понимание наблюдения, учебное наблюдение, педагогическое наблюдение, инспекторское наблюдение. Наблюдение как научный метод - это целенаправленное, планомерное и систематическое восприятие педагогических явлений, в процессе которого исследователь получает конкретный фактический материал. Наблюдение представляет собой умение вглядываться в явления окружающего мира, замечать изменения, происходящие в нем, устанавливать причины этих изменений [6, стр. 10]. Основная функция наблюдения состоит в избирательном отборе сведений об изучаемом процессе в условиях прямой и обратной связи исследователя с объектом наблюдения. Существуют следующие виды данного метода: наблюдение длительное и кратковременное, сравнительное и повторное, распознающегося характера, репродуктивного характера, наблюдение за изменением и преобразованием объектов. Наблюдение направлено на вскрытие существенных взаимосвязей и отношений в наблюдаемой действительности. Тщательно подготовленная процедура наблюдений обеспечивает фиксацию всех значимых элементов ситуации. Тем самым создаются предпосылки для ее объективного изучения. Педагогическое наблюдение - это непосредственное восприятие, познание педагогического процесса в естественных условиях [4, стр. 141]. Результаты наблюдения зависят от умения целостно воспринимать наблюдаемую 
ситуацию, замечать не только относительно ясные внешние приметы деятельности, но и фиксировать малозаметные черты поведения наблюдаемых $[2]$.

Хорошая речь связана с хорошей дикцией. Невозможно добиться положительных результатов в развитии дикции, если не разобраться в причинах нарушений речи. Лишь изредка они связаны с проблемами со здоровьем. Даже если студент умеет хорошо говорить, правильно произнося все звуки, в особо значимых ситуациях его речь может стать смазанной и нечеткой. Так как при произношении слов артикуляционному аппарату необходимо очень быстро переключаться от одного движения к другому. Достигается же это только при активной и интенсивной работе мышц, которые необходимо тренировать.

Однако главной причиной невнятной, тихой речи является застенчивость студентов колледжа и отсутствие уверенности в собственных силах. В такой ситуации развитие дикции - проблема второстепенная. Прежде всего, необходима работа над собственным характером и борьба с комплексами [5].

Наблюдение как педагогический метод исследования отличается от бытовой фиксации событий, что находит отражение в требованиях к наблюдению, именно:

1. Целенаправленность. Постановка четкой, корректно сформулированной цели. Формулировка цели наблюдения зависит от задач конкретного исследования. Задачей нашего исследования является - выявить научно-педагогические основания использования интеракционных средств в развитии коммуникативных способностей студентов колледжа. Цель наблюдения - выявление средств, влияющих на развитие коммуникативных способностей студентов колледжа, использование качественной характеристики таких средств.

2. Объективность. Исключает возможность отбора только той информации, которая «работает» на подтверждение гипотезы исследования. Во время наблюдения фиксируются все факты, отвечающие задачам наблюдения, даже те, которые противоречат гипотезе и концепции исследования. В нашем исследовании мы выдвигаем гипотезу: четкая речь и хорошо поставленный голос студентов колледжа зависит от долгой и упорной работы над собой, включающей выполнение упражнений по развитию дикции.

3. Наличие плана наблюдения. В плане определяются цель и предполагаемый результат наблюдения, объект, предмет, ситуация и способ 
наблюдения, выявляемые параметры и единицы наблюдения, продолжительность наблюдения, способ регистрации наблюдаемого.

4. Разработка процедуры. Заблаговременная разработка процедуры наблюдения и формы фиксации наблюдаемых фактов (в нашем эксперименте протокол наблюдения в форме таблицы) и формулирования промежуточных выводов.

5. Учет возможных ошибок. Исследователь должен знать типичные ошибки при проведении наблюдения, причины их возникновения (например, стереотипы восприятия) и способы их минимизации.

6. Возможность сравнения, измерения, математической обработки полученных сведений. В нашем эксперименте мы будем использовать для этого методы сравнения и измерения и качественную интерпретацию полученных результатов.

7. Необходимое и достаточное количество наблюдаемых признаков. Количество наблюдаемых признаков должно быть минимальным. Это значительно облегчает наблюдение и повышает степень достоверности его результатов. В нашем эксперименте мы наблюдаем за 3 признаками интеракционных умений (первыми начать диалог, умение слушать, грамотное изложение своей точки зрения). Принимают участие в эксперименте 10 студентов колледжа.

8. Оптимальность. Условия наблюдения не должны оказывать влияние на наблюдаемый объект (не искажать обычное поведение студентов, сохранять естественный характер отношений в педагогическом процессе).

При организации наблюдения мы составили план и программу.

В программе указываются: вид наблюдения, время, продолжительность и порядок организации. В плане наблюдения отражаются основные вопросы, подлежащие изучению, на основе плана осуществляется фиксация результатов наблюдения.

\section{Программа наблюдения.}

Вид наблюдения: непосредственное, открытое, невключенное, выборочное, долгосрочное, внешнее.

Период: 90 дней.

Цель: выявление средств, влияющих на развитие коммуникативных способностей студентов колледжа, использование качественной характеристики таких средств методом сравнительного анализа.

Объект: интеракционные умения. 
Предмет: вербальные и невербальные акты поведения субъектов педагогического процесса.

Ситуация: внеклассные часы студентов колледжа.

Способ наблюдения: общение со студентами колледжа.

Выявляемые параметры и единицы наблюдения (табл. 1), карта наблюдения (табл. 2)

Таблица 1

\section{Выявляемые параметры и единицы наблюдения}

\begin{tabular}{|c|c|}
\hline Средства обучения & $\begin{array}{l}\text { Применение техник и упражнений для } \\
\text { развития речи }\end{array}$ \\
\hline Наглядные пособия & $\begin{array}{l}\text { Скороговорки, выделенные на отдельных } \\
\text { листах, просмотр мотивационных } \\
\text { фильмов с речью ораторов с правильной } \\
\text { дикцией, прослушивание музыки для } \\
\text { восприятия речи как семинотное звучание }\end{array}$ \\
\hline $\begin{array}{c}\text { Количество участников } \\
\text { эксперимента }\end{array}$ & 10 студентов одной группы 1 курса \\
\hline Наблюдаемая ситуация & $\begin{array}{l}\text { Взаимоотношения студентов между } \\
\text { собой, с другими участниками } \\
\text { образовательного процесса, выступления } \\
\text { на конференциях, в аудитории }\end{array}$ \\
\hline $\begin{array}{c}\text { Критерии оценки наблюдаемых } \\
\text { явлений }\end{array}$ & $\begin{array}{l}\text { Количество, качество задаваемых } \\
\text { студентами вопросов, количество } \\
\text { пояснений и уточнений заданий, } \\
\text { эмоциональное отношение, проявление } \\
\text { творческого подхода при выполнении } \\
\text { заданий }\end{array}$ \\
\hline $\begin{array}{c}\text { Методики и техники накопления и } \\
\text { фиксирования фактов }\end{array}$ & $\begin{array}{l}\text { Заполнение дневника и оформление } \\
\text { записей в виде различных схем (карта } \\
\text { наблюдений) }\end{array}$ \\
\hline Используемые методы обучения & $\begin{array}{l}\text { Объяснительно-иллюстративные, } \\
\text { сравнительный метод, репродуктивные, } \\
\text { частично-поисковые, исследовательские } \\
\text { методы, методы контроля и самоконтроля }\end{array}$ \\
\hline $\begin{array}{c}\text { В какой мере применяемые методы } \\
\text { и приемы соответствовали } \\
\text { поставленным задачам }\end{array}$ & $\begin{array}{l}\text { Выводы и подведение итогов по } \\
\text { результатам эксперимента }\end{array}$ \\
\hline
\end{tabular}


Таблица 2

Карта наблюдения

\begin{tabular}{|c|c|c|c|c|}
\hline $\begin{array}{c}\text { Предмет } \\
\text { наблюдения }\end{array}$ & $\begin{array}{c}\text { Важно обратить } \\
\text { внимание }\end{array}$ & $\begin{array}{l}\text { Текущие } \\
\text { заметки }\end{array}$ & $\begin{array}{c}\text { Выводы, } \\
\text { направленные } \\
\text { на решение } \\
\text { учебно- } \\
\text { воспитательных } \\
\text { и } \\
\text { коррекционно- } \\
\text { развивающих } \\
\text { задач }\end{array}$ & $\begin{array}{c}\text { Выводы о } \\
\text { личностных } \\
\text { особенностях, } \\
\text { характеризующих } \\
\text { обучающегося }\end{array}$ \\
\hline $\begin{array}{l}\text { Первыми } \\
\text { вступать в } \\
\text { диалог } \\
\text { (познакомиться, } \\
\text { дать пояснение). } \\
\text { Умение } \\
\text { слушать. }\end{array}$ & \multirow{2}{*}{$\begin{array}{l}\text { Описание фактов } \\
\text { учебной и } \\
\text { интеллектуальной } \\
\text { деятельности } \\
\text { студентов: } \\
\text { - особенности } \\
\text { проявления } \\
\text { свойств и видов } \\
\text { внимания; } \\
\text { - качество } \\
\text { выполнения } \\
\text { заданий; } \\
\text { - особенности } \\
\text { восприятия, } \\
\text { запоминания и } \\
\text { воспроизведения } \\
\text { учебного } \\
\text { материала; } \\
\text { - активизация } \\
\text { мыслительной } \\
\text { деятельности, } \\
\text { творческого } \\
\text { воображения; } \\
\text { - факты } \\
\text { поведения } \\
\text { студентов, их } \\
\text { действий, } \\
\text { общения, } \\
\text { отношений с } \\
\text { преподавателями } \\
\text { и между собой. }\end{array}$} & \multirow{2}{*}{$\begin{array}{l}\text { Фиксировать } \\
\text { все внешние } \\
\text { проявления: } \\
\text { движения, } \\
\text { позы, речь, } \\
\text { мимику. По } \\
\text { данным } \\
\text { проявлениям } \\
\text { можно } \\
\text { судить о } \\
\text { внимании } \\
\text { студентов. }\end{array}$} & \multirow{2}{*}{$\begin{array}{l}\text { Отметить время } \\
\text { начала и } \\
\text { окончания } \\
\text { деятельности, } \\
\text { направленной на } \\
\text { развитие речи, } \\
\text { фиксировать } \\
\text { отвлечение, } \\
\text { переключение, } \\
\text { распределение } \\
\text { внимания во } \\
\text { время } \\
\text { выполнения } \\
\text { практик по } \\
\text { развитию речи. }\end{array}$} & \multirow{2}{*}{$\begin{array}{l}\text { Личностные черты } \\
\text { характера, } \\
\text { интеллектуальные } \\
\text { свойства, } \\
\text { способности, } \\
\text { отношение к учению и } \\
\text { др. Применяется } \\
\text { сравнительный метод } \\
\text { наблюдения с } \\
\text { показателями и } \\
\text { данными о студентах, } \\
\text { полученными с } \\
\text { помощью других } \\
\text { методов и } \\
\text { психодиагностических } \\
\text { методик, и делаются } \\
\text { обоснованные, } \\
\text { аргументированные } \\
\text { выводы, } \\
\text { характеризующие } \\
\text { личность студентов. }\end{array}$} \\
\hline $\begin{array}{l}\text { Правильно, } \\
\text { грамотно и } \\
\text { понятно } \\
\text { излагать свои } \\
\text { мысли, чувства } \\
\text { и желания на } \\
\text { родном языке, } \\
\text { используя при } \\
\text { этом устную } \\
\text { речь. }\end{array}$ & & & & \\
\hline
\end{tabular}

В процессе эксперимента проходило наблюдение за 10 студентами одной группы первого курса обучения социально-экономического колледжа. По ходу эксперимента для развития коммуникативных способностей, в нашем случае это предмет наблюдения, были применены следующие методы и практики. Первое основное правило - побороть страх общения. Не нужно стесняться идти на контакт первым. Если хотите общения - просто начинайте его. Необходимо 
учитывать, что есть ситуации, когда потенциальный собеседник не желает общаться, поэтому не стоит на него давить и принуждать. В остальных же случаях нужно учиться переступать через свои комплексы и неуверенность [7, стр. 9].

Умение контролировать дыхание. Без него текст может прерываться паузами и вдохами в тех местах, где это нарушает его смысл или ухудшает эмоциональность. В результате речь станет обрывистой, а смысл сказанного воспринимается хуже. Поэтому одним из первых упражнений по развитию дикции должны стать тренировки для выработки правильного дыхания:

Прямой путь к общению - это открытость. Никто не запрещает смеяться, грустить, признаваться в любви, высказывать опасения делиться своими наблюдениями и идеями, мыслями, даже если вас сможет понять не каждый, но с помощью открытости и искренности возрастает вероятность найти единомышленников и друзей. Также открытость способствует повышению самооценки и формированию положительного взгляда на мир.

Умение слушать - один из лучших способов услышать, понять и расположить к себе собеседника. Слушая не перебивая, вы не только даете собеседнику пространство для выражения своих мыслей, но и сами получаете о нем массу информации, а также сможете увидеть, какие ошибки в общении допускает он, чтобы не повторять их в собственном общении. Также в процессе активного слушания можно отследить свои реакции на поведение человека, а значит, научиться видеть себя со стороны.

Один из ключевых моментов в искусстве общения - уметь принимать чужую точку зрения. Оппоненту не всегда следует говорить, что он не прав. Достаточно просто сказать, что у вас есть свое мнение по спорному вопросу.

Помнить о собеседнике. Общаясь, постоянно отслеживайте состояние партнера: не устал ли он, интересно ли ему, хочет ли он вас слушать и т. д. Чем внимательнее вы будете к окружающим, тем выше станет ваш коммуникативный уровень, тем приятнее будет общение.

Всегда искать положительные моменты в любом разговоре, даже в неудавшемся. Фокусироваться нужно на плюсах коммуникации, поэтому в процессе концентрируйтесь на получении информации, попытках найти общий язык и понять собеседника, обратной связи. Если что-то вдруг пошло не так, не придавайте этому значения, а ищите ловкий выход из ситуации [8, стр. 25].

Тренировки. Классическим вариантом тренировки для развития дикции считаются скороговорки. Чтобы добиться отличных результатов, достаточно 
ежедневно выделять на занятия не меньше 5-10 минут. Однако для развития хорошей дикции есть одно важное правило: каждую фразу нужно произносить в медленном, среднем и очень быстром темпе. Начинать можно с наиболее простых предложений, которые учат четко произносить один или два звука, а затем переходить к более сложным.

Кроме проговаривания скороговорок для развития дикции полезно читать вслух. Лучше всего делать запись голоса на диктофон. Читая отрывки из книг и делая аудиозапись, можно отрабатывать произношение до тех пор, пока оно не станет практически идеальным. При чтении вслух не допускать монотонности, менять интонацию, а также менять громкость и скорость чтения, научиться выделять паузами наиболее важные моменты, не теряя контроль, чтобы подобные паузы были уместными и не слишком затянутыми. Окружающими лучше всего воспринимается спокойный и уверенный голос. Занимаясь развитием дикции, можно научиться говорить спокойно и убедительно [3, стр. 2].

Наличие в разговорной речи слов «ну», «блин», «типа», «как бы» всегда негативно сказывается на содержании беседы. Избавившись от слов-паразитов, возрастает уверенность в себе и доверие к вашему мнению.

Важный аспект, который нужно учитывать - необходимость постоянного интеллектуального развития и пополнения словарного запаса. Хорошо развитый человек в любой ситуации может поддержать беседу и найти подходящие слова. Чтобы стать именно таким, стоит больше читать, чаще разгадывать кроссворды и посещать различные тренинги, семинары по саморазвитию.

Развитие навыков общения - это еще и развитие уверенности в себе. Студенты с адекватной самооценкой, знающие свои сильные стороны и ценящие себя, привлекают к себе единомышленников. Уверенность чувствуется, вызывает уважение и способствует тому, что окружающие сами идут на контакт.

Применяя на протяжении трехмесячного периода времени перечисленные методики, проведя сравнительную диагностику до и после эксперимента, мы получили результаты по развитию интерракционных умений, учитывая шкалу показателей от 0 до 10 (рис. 1). 


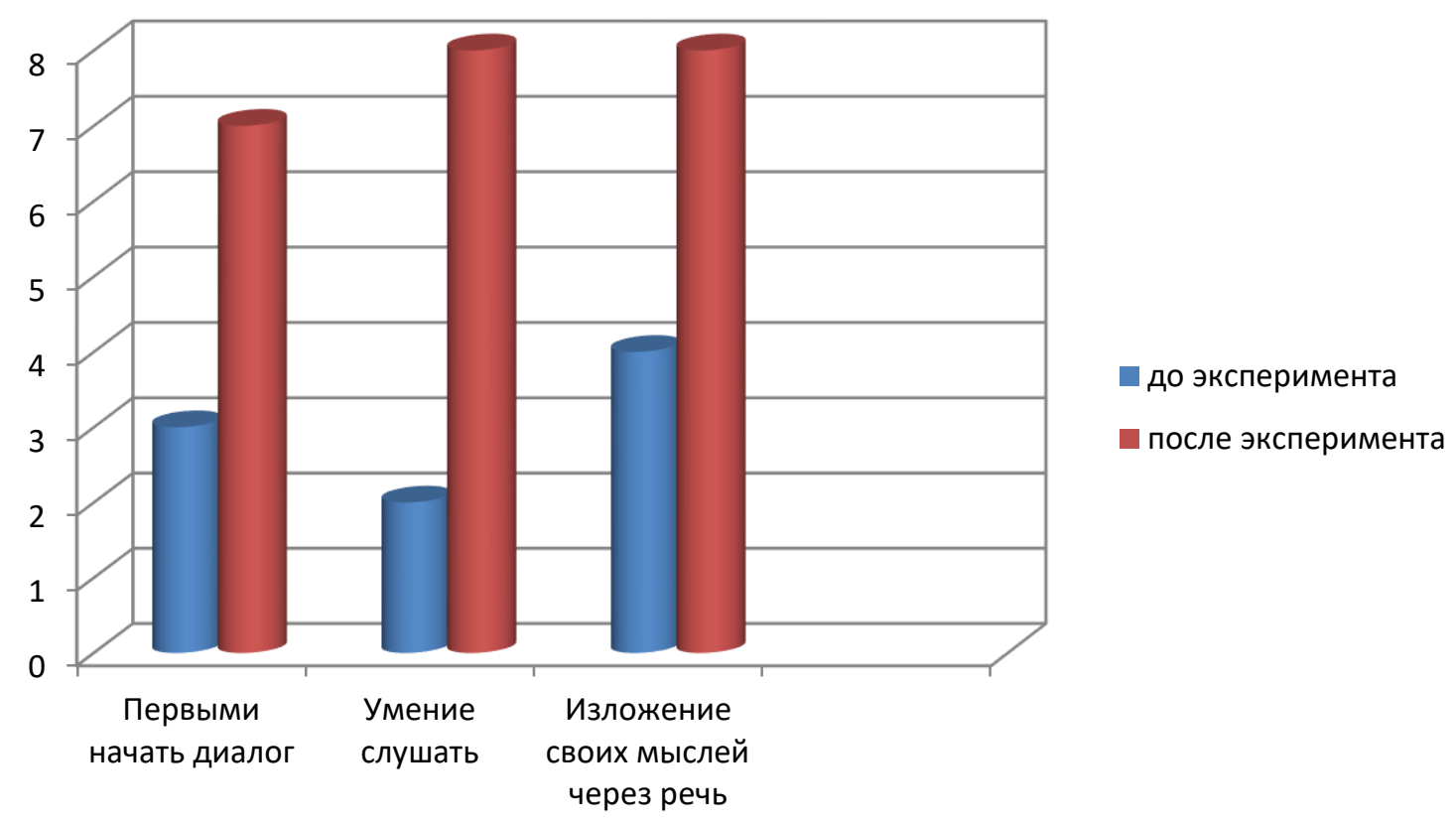

\section{Рис. 1. Результаты развития интерракционных умений студентов колледжа}

В результате исследования, мы видим, что первыми начать диалог до начала эксперимента могли 3 студента из 10, после эксперимента их стало 7. Умением слушать до начала эксперимента владели 2 студента, после освоения методик - 8. Грамотно, правильно излагать свои мысли, чувства могли до начала эксперимента 4 студента, по завершении - 8 .

\section{Выводы и результаты исследования.}

Грамотная речь или активный словарный запас способствует познанию окружающего мира, помогает самовыражению, нарабатываются коммуникативные навыки. Активно развиваются психические познавательные процессы - внимание, память, мышление, что является немаловажным для освоения образовательных программ студентами колледжа [9, стр. 16].

Можно сказать, коммуникативные способности или навыки составляют особый поведенческий комплекс, позволяющий каждому устанавливать контакты; заинтересовывать собеседника; поддерживать общение; сохранять отношения; аргументировать свои мысли; отстаивать свои интересы; разрешать конфликты; пользоваться невербальными средствами общения; защищаться от манипуляций; понимать окружающих, мотивы их действий и реакции [1, стр. 8].

По результатам проведенного наблюдения по развитию интерракционных умений студентов колледжа можно сделать вывод, что коммуникативные 
умения и способности можно развивать в любом возрасте. Для этого нужно просто задаться целью стать идеальным собеседником и постоянно тренировать свои навыки. Если ежедневно уделять несколько минут для работы над улучшением дикции, уже через несколько месяцев речь изменится, а сам голос преобразиться до неузнаваемости. При этом все приложенные усилия, несомненно, со временем будут вознаграждены.

\section{Список литературы}

1. Кривцова О.В. Прохождение собеседования : метод. пособие для студентов 3 курса / О.В. Кривцова. - Подольск : НОУ Институт экономики, 2009. - C. 18.

2. Миронов Л. Как лучше узнать ученика / Л. Миронов // Методическая работа в школе, 2010. - № 4.

3. Морина М.С. Мониторинг различных видов речевой деятельности экономистов обучения иностранному языку : метод. рекомендации / М.С. Морина. - Подольск : НОУ Институт экономики, 2004. - 8 с.

4. Найн А.Я. Профессиональная жизнедеятельность педагога: выбор стратегии : науч.-метод. пособие / А.Я. Найн, 3.М. Уметбаев. - Магнитогорск : МаГУ, 2010. - 235 с.

5. Попова Г.В. Изучение и диагностика индивидуальных особенностей личности учащихся - важнейшее условие оптимизации обучения и воспитания / Г.В. Попова [Электронный ресурс] Режим доступа https://xn-i1abbnckbmc19fb.xn--8B / 243-002- 57.

6. Практикум по возрастной и педагогической психологии. / Под ред. И.В. Дубровиной. - М., 1999.

7. Психология человека от рождения и до смерти / Под ред. А.А. Реана. - Спб. - М., 2002.

8. Сапогова Е.Е. Психология развития человека / Е.Е. Сапогова. - М., 2001.

9. Столяренко Л.Д. Основы психологии / Л.Д. Столяренко. - М., 1999. 